\title{
Effects of 5-aminolevulinic acid supplementation on milk production, iron status, and immune response of dairy cows
}

\author{
A. O. Hendawy, ${ }^{1}$ M. Shirai, ${ }^{1}$ H. Takeya, ${ }^{1}$ S. Sugimura, ${ }^{1}$ S. Miyanari, ${ }^{2}$ S. Taniguchi, ${ }^{2}$ and K. Sato ${ }^{1 *}$ \\ ${ }^{1}$ Department of Biological Production, Tokyo University of Agriculture and Technology, Tokyo 183-8509, Japan \\ ${ }^{2}$ Neopharma Japan, Tokyo 102-0071, Japan
}

\section{ABSTRACT}

The objective of this study was to investigate the effect of 5-aminolevulinic acid (5-ALA) as a dietary supplement on milk yield and composition as well as iron status and immune response in lactating dairy cows. In this study 13 lactating Holstein cows were randomly assigned to either a control group or a treatment group supplemented with $10 \mathrm{mg}$ of 5-ALA per kilogram of dry matter. During feeding, 5-ALA was mixed with a small amount of the total mixed ration and top-dressed. The experiments followed a crossover design with 2 periods. Each period consisted of an adaptation period of $12 \mathrm{~d}$ and a test period of $2 \mathrm{~d}$. Dairy cows fed the diet supplemented with 5-ALA exhibited increased counts of white blood cells and granulocytes compared with the control group. The rate of phagocytosis and mitogen-induced proliferation of peripheral blood mononuclear cells in cows fed 5-ALA were higher than in cows fed a basal diet. However, 5-ALA did not affect iron status or plasma biochemical composition. Supplementation with 5-ALA improved milk protein and milk casein contents; however, it had no effect on milk production, milk fat, lactose, total solids, or solids-not-fat, compared with the control. We conclude that dietary supplementation of 5-ALA to lactating dairy cows may have a positive effect on milk protein synthesis and the immune response.

Key words: aminolevulinic acid, dairy cow, immunomodulator, iron status

\section{INTRODUCTION}

The use of antibiotics in animal nutrition has been associated with severe health-related drawbacks (e.g., antibiotic resistance), which has led to bans on their use in several countries. Since then, various novel compounds have been investigated as possible alternatives

Received November 13, 2018.

Accepted June 12, 2019.

*Corresponding author: satokan@cc.tuat.ac.jp to antibiotics (Sato, 2016). Immunomodulators are one type of available nutritional molecules that enhance humoral immunity, minimize immunological stress, and protect against disease without decreasing production performance in farm animals (Klasing, 1998). It is common for high-producing dairy cows to experience immunosuppression during the lactation period. Depletion of immunocompetence not only increases the number of new infections leading to disease but also enhances the progression of subclinical diseases into clinical ones (Kimura et al., 1999; Wu et al., 2017). Increased incidence of disease may severely reduce milk production and quality (Goff and Horst, 1997; Drackley, 1999).

Evolving research on feed additives involves new nontraditional ones such as 5-aminolevulinic acid (5-ALA) as an immunomodulator in pigs and chickens (Chen et al., 2008; Sato et al., 2012). Studies demonstrate that 5-ALA is a product that results from condensing succinyl-CoA and Gly, which, after a chain of chemical interactions, produces heme, an essential constituent of hemoglobin (Zhu et al., 2002). Microorganisms such as Clostridium thermoaceticum, methanogens, Chlorella spp., and photosynthetic bacteria produce ALA in considerable amounts (Nishikawa and Murooka, 2001), which can be introduced to livestock as a feed additive. Supplementation of 5-ALA in the diet of sows enhances general health, improves immune response, and increases resistance to disease (Cho and Kim, 2011). The plasma tumor necrosis factor- $\alpha$ concentration in weanling pigs supplemented with $10 \mathrm{mg}$ of 5 -ALA per kilogram of feed was significantly lower than that in the controls at 2 or $4 \mathrm{~h}$ after Escherichia coli LPS injections (Chen et al., 2008). Moreover, dietary supplementation of 5-ALA improved functions of the immune system and enhanced growth performance in broiler chickens (Sato et al., 2012).

Although a considerable number of studies have examined the effects of 5-ALA in chickens and pigs, to our knowledge no studies have yet investigated the effects of 5-ALA supplementation in dairy cows. Based on the aforementioned literature, we hypothesized that dietary 5 -ALA supplementation at a level of $10 \mathrm{mg} / \mathrm{kg}$ of DM 
might improve the immune function as indicated by blood phagocytes and mitogen [concanavalin A (Con A) and phytohemagglutinin (PHA)]-induced proliferation of peripheral blood mononuclear cells (PBMC). The present study also examined the effects of 5-ALA on milk production and composition as well as on iron status in lactating dairy cows.

\section{MATERIALS AND METHODS}

\section{Animals and Treatments}

A total of 13 multiparous Holstein cows (average BW of $713 \pm 19 \mathrm{~kg}$, milk production of $23.1 \pm 1.8 \mathrm{~kg} / \mathrm{d}$, $219 \pm 36$ DIM, and lactation number $2.8 \pm 0.6 ; \pm \mathrm{SD}$ ) were housed in a freestall barn. Two experiments were performed, and the analyses combined both groups of animals. However, some outcome measures were evaluated only in one experiment $(\mathrm{n}=6$ cows). In every experiment, cows were randomly assigned to either the control group, which was fed only the basal TMR, or the treatment group, which consisted of the basal TMR supplemented with $10 \mathrm{mg}$ of 5-ALA per kilogram of DM (Table 1). The 5-ALA was provided by Neopharma Japan (Tokyo; $1 \%$ 5-ALA with silica). The 5-ALA was mixed with a portion of the TMR and top-dressed on the delivered feed. Feed and water were provided ad libitum. The supplementation rate of 5-ALA used in this study was based on supplementation rates used in experiments with sows. The present experiment used a crossover design with 2 periods. Each period comprised an adaptation period of $12 \mathrm{~d}$ and a test period of $2 \mathrm{~d}$. Cows were milked at 0900 and $1700 \mathrm{~h}$, and they were fed after milking. The Animal Care and Use Committee of the Tokyo University of Agriculture and Technology approved all procedures of the current study.

\section{Sampling of Blood and Milk}

Blood samples were collected from the jugular vein $5 \mathrm{~h}$ after feeding on the last day of each period (with heparin as an anticoagulant) to obtain whole blood, plasma, and PBMC. Each heparinized blood sample was divided into 3 portions. The first portion was used to measure blood hematology: red blood cell count (RBC), hemoglobin and hematocrit levels, mean corpuscular volume (MCV), mean corpuscular hemoglobin level, mean corpuscular hemoglobin concentration, platelet and white blood cell (WBC) counts, and differential count of WBC by automatic blood analyzer (Nihon Kohden, Celltac Alpha, Tokyo, Japan). The second portion was centrifuged at 3,000 $\times g$ for $15 \mathrm{~min}$ at $4^{\circ} \mathrm{C}$ to obtain plasma. Plasma samples were stored at $-30^{\circ} \mathrm{C}$ until biochemical analysis. The third portion was used to obtain PBMC.

Milk yield was automatically recorded at each milking, with data used only from the last $2 \mathrm{~d}$ of each period. Milk was sampled according to the milk yield of each cow during the last $2 \mathrm{~d}$ of each period. Samples of milk were stored at $-30^{\circ} \mathrm{C}$ until analysis of milk composition.

\section{Chemical Analysis of Plasma and Milk}

Plasma concentrations of glucose, fatty acids, triglyceride, total cholesterol, and BUN were analyzed using an assay kit from Wako Pure Chemical Co. (Osaka, Japan), and iron and unsaturated iron binding capacity were analyzed using an assay kit from Metallogenics Co., Ltd. (Chiba, Japan), each according to manufacturers' instructions. Milk composition-fat, protein, lactose, CN, TS, SNF, MUN, and SCC - was measured via semiautomatic infrared spectroscopy (Milko-Scan 133N, Foss Electric, Hillerød, Denmark).

\section{Immunological Assay}

Preparation of PBMC Suspensions from Blood Samples. The PBMC were isolated from whole blood via density gradient separation, as described in a previous report (Sato et al., 2012). Briefly, the PBMC suspensions from blood samples were gently added to Histopaque-1077 tubes (Sigma-Aldrich, St. Louis, MO). Centrifugation was performed at $400 \times g$ for 50 min at

Table 1. Ingredient and nutrient composition of basal diet

\begin{tabular}{lc}
\hline Composition & Diet, \% of DM \\
\hline Ingredient & 34.0 \\
Corn silage & 9.60 \\
Sudangrass hay & 11.2 \\
Alfalfa hay cube & 20.8 \\
Concentrate mixure $^{1}$ & 11.2 \\
Wheat bran & 7.60 \\
Soybean meal & 5.70 \\
Rice bran & \\
Nutrient composition & \\
TDN & 72.7 \\
CP & 16.9 \\
Ether extract & 3.70 \\
NDF & 36.9 \\
\hline
\end{tabular}

${ }^{1}$ Contained $47 \%$ grain (heat-treated corn, barley, wheat flour, milo, ray), $27 \%$ wheat bran, rice bran, and corn gluten feed $22 \%$ oil seed meals (soybean meal, rapeseed meal, corn gluten meal, linseed meal) and $4 \%$ others (molasses, calcium carbonate, sodium chloride, dicalcium phosphate)

${ }^{2}$ Estimated from Standard Tables of Feed Composition in Japan (Agriculture, Forestry and Fisheries Research Council Secretariat, 2006). 
$15^{\circ} \mathrm{C}$. The boundary layers between the medium with blood and Histopaque-1077 were collected as PBMC. The resulting PBMC were washed 3 times with RPMI 1640 medium (Sigma-Aldrich).

Determination of $P B M C$ Proliferation. The isolated PBMC were suspended in RPMI 1640 containing $10 \%$ fetal bovine serum. The PBMC were diluted at $2.5 \times 10^{6}$ cells $/ \mathrm{mL}$, and aliquots of $150 \mu \mathrm{L}$ of cells per well were plated in triplicate into flat-bottom 96-well culture plates and incubated at $37^{\circ} \mathrm{C}$ in a humidified $5 \% \mathrm{CO}_{2}$ atmosphere. T-cell proliferation was induced by Con A $(40 \mu \mathrm{g} / \mathrm{mL})$ or PHA $(20 \mu \mathrm{g} / \mathrm{mL})$ stimulation for $48 \mathrm{~h}$ (Takahashi et al., 2010). Cell proliferation was measured using a Cell Counting Kit- 8 according to the manufacturer's guidelines (Dojindo, Osaka, Japan). Results were expressed as an arbitrary unit on the basis of absorbance (A) values (A450 to A655 nm of cells cultured with Con A; A450 to A655 nm of cells cultured without Con A) of the PBMC.

Analysis of Blood Phagocytosis. The isolated PBMC were diluted to a concentration of $2.5 \times 10^{6}$ cells/mL with Hanks' balanced salt solution with 20 $\mathrm{m} M$ HEPES ( $\mathrm{pH}$ 7.4). Then they were preincubated at $37^{\circ} \mathrm{C}$ for $2 \mathrm{~min}$. After that, the cells were incubated with luminol-bound microbeads (Kamakura TechnoScience Inc., Kanagawa, Japan; catalog no. KTS405). Chemiluminescence from cells that ingested the beads was measured on a TD-20/20 luminometer (Promega, Fitchburg, WI) for $15 \mathrm{~s}$ every $1 \mathrm{~min}$, up to $15 \mathrm{~min}$. These data indicated the rate of cell phagocytosis.

\section{Calculation and Statistical Analysis}

Total iron binding capacity (TIBC) was calculated by summing iron and unsaturated iron binding capacity. The percentage of transferrin saturation was computed according to the following formula: the percentage of transferrin saturation $=$ iron $(\mu \mathrm{g} / \mathrm{dL}) / \mathrm{TIBC}(\mu \mathrm{g} / \mathrm{dL})$ $\times 100$. Averaged milk yield and milk composition data were used to calculate yields of milk fat, protein, lactose, and CN. Feed efficiency was calculated as milk yield $(\mathrm{kg} / \mathrm{d})$ divided by kilograms of DMI. Energycorrected milk was calculated by an equation developed by Sjaunja et al., (1990): ECM $(\mathrm{kg} / \mathrm{d})=\mathrm{kg}$ of milk $\times[(38.3 \times \%$ fat $\times 10+24.2 \times \%$ true protein $\times 10$ $+16.54 \times \%$ lactose $\times 10+20.7) \div 3,140]$. Energycorrected milk efficiency was calculated as ECM $(\mathrm{kg} / \mathrm{d})$ divided by kilograms of DMI. Data were analyzed using the MIXED procedure of SPSS (PASW Statistics 18.0, SPSS Inc., Chicago, IL) assuming a crossover design. Cow was the experimental unit. The model included treatment, period, and experiment as fixed effects and cow as a random effect. Data are presented as means
Table 2. Effects of basal diet (control) vs. 5-aminolevulinic acid (5-ALA) supplementation on milk yield and composition of 13 multiparous lactating Holstein dairy cows

\begin{tabular}{|c|c|c|c|c|}
\hline Item & Control & 5-ALA & SEM & $P$-value \\
\hline DMI, kg/d & 20.2 & 20.2 & 0.96 & 0.23 \\
\hline Milk yield, $\mathrm{kg} / \mathrm{d}$ & 23.0 & 23.0 & 1.09 & 0.96 \\
\hline Feed efficiency, ${ }^{1} \mathrm{~kg} / \mathrm{kg}$ & 1.14 & 1.14 & 0.04 & 0.88 \\
\hline \multicolumn{5}{|l|}{ Composition, \% } \\
\hline Fat & 4.43 & 4.46 & 0.08 & 0.83 \\
\hline Protein & 3.73 & 3.79 & 0.09 & 0.04 \\
\hline Lactose & 4.65 & 4.67 & 0.04 & 0.63 \\
\hline SNF & 9.04 & 9.10 & 0.08 & 0.39 \\
\hline TS & 13.5 & 13.5 & 0.15 & 0.67 \\
\hline $\mathrm{CN}$ & 2.73 & 3.02 & 0.11 & 0.01 \\
\hline \multicolumn{5}{|l|}{ Yield, ${ }^{2} \mathrm{~kg} / \mathrm{d}$} \\
\hline Fat & 1.04 & 1.02 & 0.04 & 0.67 \\
\hline Protein & 0.83 & 0.90 & 0.04 & 0.02 \\
\hline Lactose & 1.09 & 1.09 & 0.06 & 0.89 \\
\hline SNF & 2.11 & 2.12 & 0.09 & 0.93 \\
\hline TS & 3.14 & 3.13 & 0.12 & 0.89 \\
\hline $\mathrm{CN}$ & 0.62 & 0.69 & 0.03 & 0.03 \\
\hline $\mathrm{ECM},{ }^{3} \mathrm{~kg} / \mathrm{d}$ & 23.2 & 24.7 & 1.17 & 0.09 \\
\hline ECM feed efficiency, ${ }^{4} \mathrm{~kg} / \mathrm{kg}$ & 1.15 & 1.23 & 0.04 & 0.18 \\
\hline MUN, mg/dL & 13.5 & 13.7 & 0.71 & 0.81 \\
\hline $\mathrm{SCC}, \times 10^{3}$ cells $/ \mathrm{mL}$ & 10.2 & 8.30 & 1.04 & 0.17 \\
\hline
\end{tabular}

${ }^{1}$ Milk yield $\div$ DMI.

${ }^{2}$ Yield of milk components and ECM were calculated with milk yield for the day of milk sampling.

${ }^{3}$ Energy-corrected milk $(\mathrm{kg} / \mathrm{d})=\mathrm{kg}$ of milk $\times[(38.3 \times \%$ fat $\times 10+$ $24.2 \times \%$ true protein $\times 10+16.54 \times \%$ lactose $\times 10+20.7) \div 3,140]$; Sjaunja et al. (1990).

${ }^{4} \mathrm{ECM} \div$ DMI.

with standard error (SE). Statistical differences were considered significant at $P<0.05$. Differences between treatments with $0.05 \leq P<0.10$ were considered a trend toward significance.

\section{RESULTS}

\section{Milk Production and Composition}

Table 2 shows the effects of 5-ALA on DMI, milk yield, and milk composition. Supplementation of 5-ALA improved the milk protein and $\mathrm{CN}$ concentration and yields $(P=0.04$ and 0.01 , respectively). Supplementation also tended to increase ECM $(P=0.09)$; however, 5 -ALA supplementation had no effect on milk yield, levels of milk fat, lactose, SNF, TS, and MUN, or SCC.

\section{Hematological Parameters and Immune Response}

Cows fed 5-ALA had higher numbers of WBC and granulocytes (neutrophils and basophils) than did cows fed basal diet only $(P=0.02$ and $P<0.01$, respectively). Lymphocytes also tended to increase with supplementation $(P=0.06)$. However, we observed no differences in any other hematological measures in the 
Table 3. Effects of basal diet (control) vs. 5-aminolevulinic acid (5-ALA) supplementation on hematological parameters of multiparous lactating Holstein dairy cows ${ }^{1}$

\begin{tabular}{lcccc}
\hline Item & Control & 5-ALA & SEM & $P$-value \\
\hline Red blood cells, $10^{6} / \mu \mathrm{L}$ & 5.59 & 5.63 & 0.11 & 0.81 \\
Hemoglobin, g/dL & 7.90 & 8.09 & 0.14 & 0.33 \\
Hematocrit, $\%$ & 25.3 & 26.2 & 0.53 & 0.22 \\
Mean corpuscular volume, fL & 45.3 & 46.3 & 0.55 & 0.20 \\
Mean corpuscular hemoglobin, pg & 14.2 & 14.4 & 0.18 & 0.21 \\
Mean corpuscular hemoglobin concentration, g/dL & 31.3 & 31.2 & 0.11 & 0.69 \\
Platelets, $10^{3} / \mu \mathrm{L}$ & 399 & 398 & 12.9 & 0.31 \\
White blood cells, $10^{3} / \mu \mathrm{L}$ & 6.43 & 7.07 & 0.19 & 0.02 \\
Lymphocytes, $10^{3} / \mu \mathrm{L}$ & 2.57 & 2.97 & 0.17 & 0.06 \\
Monocytes, $10^{3} / \mu \mathrm{L}$ & 0.06 & 0.08 & 0.07 & 0.34 \\
Eosinocytes, $10^{3} / \mu \mathrm{L}$ & 0.39 & 0.33 & 0.06 & 0.31 \\
Granulocytes, $10^{3} / \mu \mathrm{L}$ & 3.39 & 3.76 & 0.09 & $<0.01$ \\
\hline
\end{tabular}

${ }^{1}$ Data for mean corpuscular volume, mean corpuscular hemoglobin level, mean corpuscular hemoglobin concentration, and platelets were measured for 6 cows.

current study, including RBC, levels of hemoglobin and hematocrit, MCV, mean corpuscular hemoglobin level, mean corpuscular hemoglobin concentration, or counts of platelets, monocytes, and eosinophils (Table 3).

Rates of phagocytosis and PHA-induced proliferation of PBMC increased in dairy cows fed diets supplemented with 5-ALA compared with dairy cows fed a basal $\operatorname{diet}(P<0.01$ and $P=0.02$, respectively). Moreover, Con A-induced proliferation of PBMC increased with 5-ALA supplementation; however, that change was insignificant (Table 4).

\section{Biochemical Composition of the Plasma and Iron Status}

All the parameters that portray the biochemical compositions of plasma remained unchanged in response to 5-ALA supplementation (data not shown). Supplementation of 5-ALA did not exert any effect on indicators of iron status in either plasma or milk (Table 5).

\section{DISCUSSION}

Dietary supplementation of 5-ALA improved the inflammatory responses and iron status in both chickens and pigs (Min et al., 2004; Chen et al., 2008; Sato et al., 2012). A recent study showed that 5-ALA oxidation products stimulated the patterns of protein regulation, which suggests an effect of 5-ALA on interconnections among cellular processes such as the intrinsic pathway of apoptosis, redox homeostasis, cell proliferation, lipid metabolism, and DNA repair in rat hepatocytes (Menezes et al., 2018). If so, 5-ALA could be useful as an immunomodulator or a metabolic modulator in monogastric animals. However, we could not locate any report on the effects of 5-ALA supplementation to diets of ruminants, given the complexity of ruminants' stomachs. Evidence indicates that rumen microbes rapidly degrade and use nutrients supplemented to dairy cows, such as carbohydrates, vitamins, and amino acids (Slyter, 1976; Aoki et al., 2013). It is likely, therefore, that rumen microbes may quickly break down 5-ALA. The present study, however, revealed that milk protein and $\mathrm{CN}$ contents, as well as WBC and granulocyte counts, PHA-induced proliferation of PBMC, and rate of phagocytosis were higher in cows fed 5-ALA compared with cows receiving the control diet. These results clearly show that 5-ALA is an immunomodulator in ruminant animals, similar to previous findings in pigs and chickens. Moreover, 5-ALA improved milk composition in dairy cows.

Regarding the effect of 5-ALA on the immune response, the novel finding of the present study is that PHA-induced proliferation of PBMC significantly increased in dairy cows fed a diet supplemented with 5-ALA compared with dairy cows fed a basal diet. Moreover, Con A-induced proliferation of PBMC increased with supplementation of 5-ALA; however, that increase was insignificant. In accordance with our results, mitogen-induced proliferation of splenic monocular cells in chickens fed 10 or $100 \mathrm{mg}$ of 5-ALA per kilogram of feed was significantly greater than that in those fed basal diet or 1,000 mg of 5-ALA per kilogram of DM (Sato et

Table 4. Effects of basal diet (control) vs. 5-aminolevulinic acid (5ALA) supplementation on some immune indices of 13 multiparous lactating Holstein dairy cows

\begin{tabular}{lcccr}
\hline Item & Control & 5-ALA & SEM & $P$-value \\
\hline Concanavalin A, S.I. $^{1}$ & 1.19 & 1.69 & 0.21 & 0.10 \\
Phytohemagglutinin, S.I. $^{2}$ & 0.51 & 1.32 & 0.20 & 0.02 \\
Phagocytosis, AU $^{2}$ & 1.00 & 1.33 & 0.10 & $<0.01$
\end{tabular}

${ }^{1}$ S.I. $=$ stimulation index.

${ }^{2} \mathrm{AU}=$ arbitrary units. 
Table 5. Effect of basal diet (control) vs. 5-aminolevulinic acid (5-ALA) supplementation on iron status in plasma and milk of multiparous lactating Holstein dairy cows ${ }^{1}$

\begin{tabular}{lcccc}
\hline Item & Control & 5-ALA & SEM & $P$-value \\
\hline Plasma & & & & \\
Iron, $\mu \mathrm{g} / \mathrm{dL}$ & 157 & 163 & 8.13 & 0.73 \\
Unsaturated iron binding capacity, $\mu \mathrm{g} / \mathrm{dL}$ & 270 & 284 & 13.6 & 0.48 \\
Total iron binding capacity, $\mu \mathrm{g} / \mathrm{dL}$ & 427 & 447 & 14.9 & 0.40 \\
$\quad$ Transferrin saturation, $\%$ & 36.9 & 36.7 & 1.67 & 0.95 \\
Milk & & & & \\
Iron, $\mu \mathrm{g} / \mathrm{dL}$ & 102 & 112 & 9.37 & 0.59 \\
Unsaturated iron binding capacity, $\mu \mathrm{g} / \mathrm{dL}$ & 153 & 156 & 5.25 & 0.76 \\
Total iron binding capacity, $\mu \mathrm{g} / \mathrm{dL}$ & 255 & 268 & 9.32 & 0.41 \\
Transferrin saturation, $\%$ & 39.5 & 41.0 & 2.64 & 0.79 \\
\hline
\end{tabular}

${ }^{1}$ Data for these indices were measured for 6 cows.

al., 2012). The significant increase in PHA but not in Con A in this study may be because PHA is associated with stronger mitogen activity compared with Con A (Leino et al., 1980). In addition, the present study also showed that phagocytosis was higher in dairy cows fed diets supplemented with 5-ALA than in dairy cows fed a basal diet. Phagocytic activity is a core antibacterial defense, involving activation of the inflammatory response before the production of antibodies (Gómez and Balcázar, 2008). Moreover, the counts of WBC and granulocytes in the blood of cows fed the supplemented diet was higher than those in control cows; however, we observed no between differences in counts of monocytes or eosinophils. A few reports, in chickens and pigs, show that dietary 5-ALA supplementation increased WBC counts compared with control diets (Chen et al., 2008; Yan et al., 2010). The present study, using dairy cows, shows that 5-ALA supplementation significantly increased the counts of WBC and granulocytes compared with the control treatment. This is the first study showing a functional effect of 5-ALA on the immune system in ruminants. However, cows included in the current study were pregnant, which made it impossible for us to immune challenge them via an infectious stimulus to induce the desired acute-phase inflammatory response; the body's tissue-repair attempts that follow inflammation are associated with changes to plasma protein concentrations, increased vascular permeability, and metabolic changes that may have detrimental effects for both cows and their embryos, even in the absence of evident clinical manifestations (Bertoni et al., 2015). Therefore, future studies examining the effects of 5-ALA in immune-challenged cows (e.g., early-lactating cows) are necessary, to investigate the definite mechanisms of the improvements to the immune system induced by 5-ALA supplementation.

Concerning the effects of 5-ALA on hematological parameters and iron status, several previous studies reported enhancing effects. For instance, Hossain et al. (2016) reported that supplementation of 5-ALA (0.5 or $1 \mathrm{~g}$ per kilogram of feed) increased levels of serum hemoglobin, hematocrit, and TIBC, as well as RBC counts, in weaned piglets compared with those fed the basal diet. Furthermore, Mateo et al. (2006) confirmed that $500 \mathrm{mg}$ of 5-ALA per kilogram of feed improved RBC concentration in nursery pigs. Therefore, we hypothesized that supplementation of 5-ALA in dairy cows would improve iron status. Nonetheless, the current study revealed no effect of dietary supplementation of 5-ALA on hematological characteristics (RBC count, hemoglobin and hematocrit levels, MCV, mean corpuscular hemoglobin levels, mean corpuscular hemoglobin concentration, or platelet count) or on the parameters of iron status, including iron, unsaturated iron binding capacity, TIBC, and transferrin saturation percentage. The structural and microbial differences between ruminant animals and monogastric animals may have contributed to the inconsistencies noted between our results and those of the previous 5-ALA experiments. Furthermore, the iron-enhancing activity of ALA is stimulated by the release of reactive oxygen species such as $\mathrm{O}_{2}^{-}, \mathrm{H}_{2} \mathrm{O}_{2}$, and $\mathrm{OH}^{\bullet}$, which occurs during its enolization under neutral pH (Oteiza et al., 1995). Reactive oxygen species target heme-containing proteins (Kim et al., 1995). Meanwhile, the effect of ALA on iron metabolism is inhibited by catalysts such as superoxide dismutase (Monteiro et al., 1986), whereas the heme-degrading enzyme heme oxygenase- 1 is a catalyst that takes a major role in protecting the fetus against allo-antigens over the course of pregnancy (Schumacher and Zenclussen, 2015), which might explain the relative reduction of hemoglobin that frequently occurs during pregnancy (Figueiredo et al., 2018). Thus, in our trial, we generally concluded that pregnancy and the relatively short duration of treatment might have limited the effect of ALA treatment on iron status. In addition, the lifespan of RBC decreases with age, which is associated with an increase of MCV (Shperling and Danon, 1990). However, MCV of both treated and control cows in our study was within normal range according to 
Lumsden et al. (1980) and George et al. (2010), which highlights the lack of effect of treatment on the RBC profile.

In the current study, we found a beneficial effect of 5-ALA supplementation (10 mg per kilogram of DM) on milk protein and milk casein. These results are in agreement with other studies conducted on sows, which reported that milk protein and milk fat concentration were higher in sows fed diets with 5-ALA (10 mg per kilogram of feed) than in those fed diets without 5-ALA (Wang et al., 2009). Furthermore, dietary supplementation of 5-ALA ( 0.5 or $1 \mathrm{~g}$ per kilogram of feed) improved protein concentration in the milk of lactating sows (Lee et al., 2016). The mechanism of improvement of milk protein is unclear in the previous studies. The present findings, however, indicated no change of MUN, regardless of the group. Future studies should investigate the mechanism through which 5-ALA improves milk protein and milk casein.

\section{CONCLUSIONS}

Dairy cows fed 5-ALA (10 mg per kilogram of DM) demonstrated improvements in immune response and milk protein synthesis, although we found no effect of 5 -ALA on indicators of iron status. Nevertheless, it is necessary to conduct more research on 5-ALA in dairy cows, as well as other ruminant species, to ascertain the exact mechanism of action and the efficiency of 5-ALA in ruminants. The findings of this experiment should be interpreted with caution because of the relatively low number of experimental units, the short experimental periods, and the crossover experimental design.

\section{ACKNOWLEDGMENTS}

The authors thank S. Kobayashi and N. Komatsu (Field Science Center, Tokyo University of Agriculture and Technology, Japan) for their conscientious care of the experimental cows.

\section{REFERENCES}

Agriculture, Forestry and Fisheries Research Council Secretariat. 2006. Standard Tables of Feed Composition in Japan. Japan Livestock Industry Association, Tokyo, Japan.

Aoki, N., K. Sato, S. Kanda, K. Mukai, Y. Obara, and H. Itabashi. 2013. Time course of changes in antioxidant activity of milk from dairy cows fed a trehalose-supplemented diet. Anim. Sci. J. 84:4247. https://doi.org/10.1111/j.1740-0929.2012.01040.x.

Bertoni, G., A. Minuti, and E. Trevisi. 2015. Immune system, inflammation and nutrition in dairy cattle. Anim. Prod. Sci. 55:943-948. https://doi.org/10.1071/AN14863.

Chen, Y. J., I. H. Kim, J. H. Cho, B. J. Min, J. S. Yoo, and Q. Wang. 2008. Effect of $\delta$-aminolevulinic acid on growth performance, nutrient digestibility, blood parameters and the immune response of weanling pigs challenged with Escherichia coli lipopolysaccharide.
Livest. Sci. 114:108-116. https://doi.org/10.1016/j.livsci.2007.04 .015 .

Cho, J. H., and I. H. Kim. 2011. $\delta$-Aminolevulinic acid (ALA) as a potential feed additive in pig: A review. J. Anim. Vet. Adv. 10:1627-1630

Drackley, J. K. 1999. Biology of dairy cows during the transition period: The final frontier? J. Dairy Sci. 82:2259-2273. https://doi .org/10.3168/jds.S0022-0302(99)75474-3.

Figueiredo, A. C. M. G., I. S. Gomes-Filho, R. B. Silva, P. P. S Pereira, F. A. F. Da Mata, A. O. Lyrio, E. S. Souza, S. S. Cruz, and M. G. Pereira. 2018. Maternal anemia and low birth weight: A systematic review and meta-analysis. Nutrients 10:E601. https:// doi.org/10.3390/nu10050601.

George, J. W., J. Snipes, and V. M. Lane. 2010. Comparison of bovine hematology reference intervals from 1957 to 2006. Vet. Clin. Pathol. 39:138-148. https://doi.org/10.1111/j.1939-165X.2009 .00208.x.

Goff, J. P., and R. L. Horst. 1997. Physiological changes at parturition and their relationship to metabolic disorders. J. Dairy Sci 80:1260-1268. https://doi.org/10.3168/jds.S0022-0302(97)76055 -7 .

Gómez, G. D., and J. L. Balcázar. 2008. A review on the interactions between gut microbiota and innate immunity of fish. FEMS Immunol. Med. Microbiol. 52:145-154. https://doi.org/10.1111/j .1574-695X.2007.00343.x.

Hossain, M. M., J. W. Park, and I. H. Kim. 2016. $\delta$-Aminolevulinic acid, and lactulose supplements in weaned piglets diet: Effects on performance, fecal microbiota, and in vitro noxious gas emissions. Livest. Sci. 183:84-91. https://doi.org/10.1016/j.livsci.2015.11 .021 .

Kim, Y. M., H. A. Bergonia, C. Müller, B. R. Pitt, W. D. Watkins, and J. R. Lancaster Jr.. 1995. Nitric oxide and intracellular heme. Adv. Pharmacol. 34:277-291. https://doi.org/10.1016/S1054 -3589(08)61092-3.

Kimura, K., J. P. Goff, M. E. Kehrli, and J. A. Harp. 1999. Phenotype analysis of peripheral blood mononuclear cells in periparturient dairy cows. J. Dairy Sci. 82:315-319. https://doi.org/10.3168/jds .S0022-0302(99)75238-0.

Klasing, K. C. 1998. Nutritional modulation of resistance to infectious diseases. Poult. Sci. 77:1119-1125. https://doi.org/10.1093/ps/77 .8.1119.

Lee, S. I., T. S. Li, and I. H. Kim. 2016. Dietary supplementation of delta-aminolevulinic acid to lactating sows improves growth performance and concentration of iron and hemoglobin of suckling piglets. Indian J. Anim. Sci. 86:781-785.

Leino, A., T. Hirvonen, and E. Soppi. 1980. Ontogeny of phytohemagglutinin and concanavalin A responses in the human fetus: Effect of thymosin. Clin. Immunol. Immunopathol. 17:547-555. https:// doi.org/10.1016/0090-1229(80)90150-6.

Lumsden, J. H., K. Mullen, and R. Rowe. 1980. Hematology and biochemistry reference values for female Holstein cattle. Can. J. Comp. Med. 44:24-31.

Mateo, R. D., J. L. Morrow, J. W. Dailey, F. Ji, and S. W. Kim. 2006. Use of $\delta$-aminolevulinic acid in swine diet: Effect on growth performance, behavioral characteristics and hematological/immune status in nursery pigs. Asian-Australas. J. Anim. Sci. 19:97-101. https://doi.org/10.5713/ajas.2006.97.

Menezes, P. R., C. B. Gonzalez, A. O. DeSouza, D. A. Maria, and J. Onuki. 2018. Effect of 5-aminolevulinic acid on the expression of carcinogenesis-related proteins in cultured primary hepatocytes. Mol. Biol. Rep. 45:2801-2809. https://doi.org/10.1007/s11033-018 $-4367-5$.

Min, B. J., J. W. Hong, O. S. Kwon, D. K. Kang, and I. H. Kim. 2004. Influence of dietary $\delta$-aminolevulinic acid supplement on growth performance and hematological changes in weaned pigs. J. Korean Soc. Food Sci. Nutr. 33:1606-1610.

Monteiro, H. P., D. S. P. Abdalla, A. Faljoni-Alàrio, and E. J. H Bechara. 1986. Generation of active oxygen species during coupled autoxidation of oxyhemoglobin and $\delta$-aminolevulinic acid. Biochim. Biophys. Acta. 881:100-106. https://doi.org/10.1016/0304 $-4165(86) 90102-9$. 
Nishikawa, S., and Y. Murooka. 2001. 5-aminolevulinic acid: Production by fermentation, and agricultural and biomedical applications. Biotechnol. Genet. Eng. Rev. 18:149-170. https://doi.org/ 10.1080/02648725.2001.10648012.

Oteiza, P. I., C. Kleinman, M. Demasi, and E. J. H. Bechara. 1995. 5 -aminolevulinic acid induces iron release from ferritin. Arch. Biochem. Biophys. 316:607-611. https://doi.org/10.1006/abbi.1995 .1080 .

Sato, K. 2016. Molecular nutrition: Interaction of nutrients, gene regulations and performances. Anim. Sci. J. 87:857-862. https://doi .org/10.1111/asj.12414.

Sato, K., K. Matsushita, K. Takahashi, M. Aoki, J. Fuziwara, S. Miyanari, and T. Kamada. 2012. Dietary supplementation with 5-aminolevulinic acid modulates growth performance and inflammatory responses in broiler chickens. Poult. Sci. 91:1582-1589. https://doi.org/10.3382/ps.2010-01201.

Schumacher, A., and A. C. Zenclussen. 2015. Effects of heme oxygenase-1 on innate and adaptive immune responses promoting pregnancy success and allograft tolerance. Front. Pharmacol. 5:288. https://doi.org/10.3389/fphar.2014.00288.

Shperling, T., and D. Danon. 1990. Age population distribution of erythrocytes in young and old healthy donors. Exp. Gerontol. 25:413-422.

Sjaunja, L. O., L. Baevre, L. Junkkarinen, J. Pedersen, and J. Setala. 1990. A Nordic proposal for an energy corrected milk (ECM) formula. In 27th Session of the International Commission for Breeding and Productivity of Milk Animals, Paris, France. Wageningen Academic Publishers, Wageningen, the Netherlands.
Slyter, L. L. 1976. Influence of acidosis on rumen function. J. Anim. Sci. 43:910-929. https://doi.org/10.2527/jas1976.434910x.

Takahashi, K., A. Kitano, and Y. Akiba. 2010. Effect of L-carnitine on proliferative response and mRNA expression of some of its associated factors in splenic mononuclear cells of male broiler chicks. Anim. Sci. J. 81:215-222. https://doi.org/10.1111/j.1740-0929 2009.00732.x.

Wang, J. P., H. J. Kim, Y. J. Chen, J. S. Yoo, J. H. Cho, D. K. Kang, Y. Hyun, and I. H. Kim. 2009. Effects of delta-aminolevulinic acid and vitamin $\mathrm{C}$ supplementation on feed intake, backfat, and iron status in sows. J. Anim. Sci. 87:3589-3595. https://doi.org/10 $.2527 /$ jas.2008-1489.

Wu, Z. H., Y. Yu, G. M. Alugongo, J. X. Xiao, J. H. Li, Y. X. Li, Y. J. Wang, S. L. Li, and Z. J. Cao. 2017. Short communication: Effects of an immunomodulatory feed additive on phagocytic capacity of neutrophils and relative gene expression in circulating white blood cells of transition Holstein cows. J. Dairy Sci. 100:7549-7555. https://doi.org/10.3168/jds.2016-12528.

Yan, L., J. H. Lee, Q. W. Meng, X. Ao, and I. H. Kim. 2010. Evaluation of dietary supplementation of delta-aminolevulinic acid and chito-oligosaccharide on production performance, egg quality and hematological characteristics in laying hens. Asian-Australas. J. Anim. Sci. 23:1028-1033. https://doi.org/10.5713/ajas.2010 .90639

Zhu, Y., T. Hon, W. Ye, and L. Zhang. 2002. Heme deficiency interferes with the Ras-mitogen-activated protein kinase signaling pathway and expression of a subset of neuronal genes. Cell Growth Differ. 13:431-439. 